\section{ASPECTS OF MODERN GEOLOGY}

\section{By PROF. EDSON S. BASTIN \\ University of Chicago}

$\mathrm{F}$ OUR notable geological symposia were held on September 25 and 26 during the celebration of the fiftieth anniversary of the University of Chicago and with the co-operation of the Geological Society of America and the American Association for the Advancement of Science. All four symposia dealt with the frontiers of geological research.

The climax of the geological programme was undoubtedly the address of Reginald A. Daly, of Harvard University, on glaciation and submarine valleys. This was a remarkably lucid exposition of his hypothesis of the origin of submarine valleys by silty bottom currents or underflows operating under the general control of Pleistocene glaciation and its attendant effects on sea-levels.

\section{Clay Materials}

The first symposium, on the structure, properties and occurrence of clay materials and their practical application, was opened by Dr. Ralph E. Grim, of the Illinois Geological Survey, long a leader in clay research. Dr. Grim reviewed the old ideas of the composition of clay materials and the researches of the past fifteen years using modern research tools, that have led to the present generally accepted concept that clays are composed essentially of minute crystalline particles of one or more members of a few groups known as the clay minerals. The composition, structure and properties of these components were discussed and some new interpretations suggested.

Following this paper Dr. Sterling B. Hendricks, of the U.S. Bureau of Plant Industry, described in detail the lattice structure of many of the clay minerals.

Prof. W. P. Kelley, of the College of Agriculture of the University of California, discriminatingly reviewed the importance of clay researches to modern agriculture and emphasized the close relationship between soil science and geology.

Prof. F. H. Norton, of the Massachusetts Institute of Technology, pointed out that in addition to the clay minerals there are various mineral impurities, and that clays also contain soluble salts from the ground water which have a strong influence on their physical properties. Clay, having such a large surface, is very sensitive to adsorbed ions, and many of the variations observed in clays are traceable to this adsorbed material.

The symposium concluded with a discussion by Dr. Hans F. Winterkorn, of the College of Engineering, University of Missouri, of the importance of clay research in engineering construction, particularly of highways and dams, and the use of baseexchange and other methods for stabilizing such constructions.

\section{Coals}

The second symposium dealt with the physical constitution of coals and their practical significance and rras under the leadership of Dr. Gilbert H. Cady, long in charge of the important coal studies of the Illinois Geological Survey. Dr. Cad pointed out that a satisfactory classification of coals into types must rest upon an understanding of the physical and chemical properties of the primary components of coal-vitrain, clarain, durain and fusain. Increased knowledge of these components has led to the important practical result that it is now possible to synthesize coals or modify them to conform to petrographical specifications.

Dr. H. H. Lowry, of the Carnegie Institute of Technology, reviewed the data on the chemical nature of the banded constituents of coals and emphasized the fact that essentially distinct typos of chemical compounds peculiar to each of the banded components have not been found. Recent progress in Britain in the study of coals was reviewed by Prof. C. E. Marshall, of the University of Birming. ham, who further emphasized the increasing importance of microscopic study of both the plant and the mineral components of coals to efficient utilization. That in the United States improved marketing and utilization practice based upon the newer knowledge of coal constituents is well under way was emphasized by Capt. Louis C. McCabe, of the U.S. Quartermaster Corps. In the coking of coals and in hydrogenization, knowledge of the coal components are also of great import as emphasized by George C. Sprunk, of the U.S. Bureau of Mines, who pointed out, for example, that the portions of coal that are translucent under the microscope are readily hydrogenized and give high yields of liquid fuels, whereas components that are opaque are difficult to liquefy.

The influence of metamorphism on the coal constituents was stressed by Dr. C. E. Dapples, of Northwestern University, who pointed out that some constituents such as cannel and durain tend to resist physical change, whereas fusain, clarain, vitrain and resinous bodies alter their physical properties with increase in rank.

\section{Glacial Geology}

The third symposium was concerned with the newer developments in the field of glacial geology, princi. pally in North America, and was opened by Prof. Richard F. Flint, of Yale University. Several problems of very fundamental importance were discussed by him, one of these being the cause of the locations of the great ice caps. It has long been held that these ice caps grew in situ, but that hypothesis seems to encounter insuperable meteorological difficulties. It was pointed out that each central area of ice accumulation stands in definite relation to a high range of mountains - the Torngat Range of Labrador, the great mountains of Baffin Island, and the SwedishNorwegian mountains, respectively. It seems likely that it was on these mountains that the snow fell, forming Alpine glaciers, and that these glaciers coalesced, growing outward away from the mountains and thickening to such an extent that they became high enough and cold enough to catch snowfall themselves, thereby shifting the locus of maximum snowfall away from the mountains, and eventually allowing the ice caps to bury the mountains.

Space does not permit the mentioning of all the contributions to this symposium, but the northern extent of glaciation in North America is certainly a matter of very general interest, and according to Dr. A. L. Washburn, of Yale University, this is still an unsolved problem the solution of which is handicapped by the fact that sea ice may produce some features which simulate the work of glacier ice. Recent field investigation indicates that Victoria Island, with an area of about 79,000 square miles, and the very much smaller Royal Geographical 
Society Islands, were definitely glaciated during the Ice Age, and that glaciation of at least the southern portion of Banks Island is probable. Evidence obtained by a Canadian Government Expedition in 1908-9 suggests glaciation of Melville Island. No geological evidence seems to be on record indicating lack of glaciation on other islands in this region. It appears that glaciation was of considerable areal importance in Canada's Western Arctic, but informa. tion concerning the complete areal extent must await further expeditions.

It was emphasized by Dr. D. A. Nichols, of the Canadian Bureau of Geology and Topography, that most of the present knowledge of the glacial geology of Canada has been gleaned ineidentally to studies of other aspects of geology, notably the economic, and that great opportunities for specialized glacial studies exist. Correlation of glacial and marine features of the Atlantic Coast was considered by Prof. Paul MacClintock, of Princeton University, and the contributions of botanical studies to knowledge of post-glacial climates were presented by Prof. W. S. Cooper, of the University of Minnesota, who concluded that the record from pollen studies and the facts of plant geography apparently agree in indicating a mid-post-Pleistocene warm-dry period followed by a return towards cool-moist conditions during the last few thousand years.

\section{Petroleum}

The fourth symposium related to geological frontiers in the search for oil and was opened by A. I. Levorsen, chairman of the Research Committee of the American Association of Petroleum Geologists. Among the many interesting points brought out by $\mathrm{Mr}$. Levorsen in his discussion of trends in petroleum geology was a point often overlooked by those interested in mineral resources, namely, that petroleum reserves contrast with reserves of other mineral resources in that it is impossible to estimate them in advance of discovery by drilling. Thus, whatever may be the true reserves, estimated reserves have always been small, and continued discovery is essential to continued development.

The role of modern surface methods in the search for oil was described by $\mathrm{E}$. W. Owen, president of the American Association of Petroleum Geologists, and the role of micro-palæontology by Prof. Carey Croneis, of the University of Chicago. Dr. W. C. Krumbein, also of the University of Chicago, spoke of the importance of a fuller knowledge of the principles of sedimentation in the search for stratigraphic oil traps in contrast to structural traps.

In speaking of the role of ground water in petroleum accumulation, Prof. F. B. Plummer, of the University of Texas, concluded that recent extensive investigations of pore sizes, of the forces required to move liquid and gas hydrocarbons through them, of the variation in subsurface pressures, and of the forces due to interfacial tension, indicate that crude oil droplets cannot move through a porous sand from aynclinal positions to anticlinal positions by gravity alone. The conclusion is reached that hydrocarbons migrate largely as gas particles and partly as liquid films enveloping gas bubbles, along with the slow downward movement of the ground water towards the lower part of the region, and that as the tiny gas bubbles come within the influence of decidedly low pressures they accumulate in the trap.

\section{FOOD INVESTIGATIONS IN CANADA}

HOOD studies constitute a very important field of 4 research. In the National Research Laboratories at Ottawa nearly one half of the work in the Division of Biology and Agriculture now relates to food. Preparation, processing, packaging and preservation during transport are all subjects of research.

Since the autumn of 1939 the investigations in the food laboratories of the National Research Council have been directed almost wholly to new problems arising from the War. Among these is improved preservation of perishable products such as bacon and eggs shipped to Great Britain, the object being to overcome the effects of the longer shipping period and the lack of refrigerated space. The utilization of market poultry and other perishable products for which the export market has been reduced, and improvements in the nutritional value of canned goods and other processed foods have been studied. Special problems such as the storage of blood for transfusion, which the storage laboratories are well equipped to study, have also been given attention.

\section{Poultry}

One of the first problems undertaken in the food storage laboratories dealt with the preservation of dressed poultry in the frozen state. The results of this study led to definite recommendations as to precooling, freezing, packaging and storage practices that should be followed to avoid impairment in appearance or eating quality. A new package was designed to facilitate moisture-proof sealing of the product in order to prevent deterioration from surface-drying during storage.

The use of the improved package for dressed poultry for export has been restricted owing to the shortage of refrigerated space on ocean-going vessels. This emphasized the importance of canning. A canning laboratory was established towards the end of 1939 and has now been almost completely equipped.

Following a preliminary survey of the canned poultry on the domestic market, improved methods of processing have been developed and their suitability to plant conditions demonstrated. The recommended processes include pressure pre-cooking, retort precooking, improved methods of handling the raw and finished product and broth, and the use of sideopening cans, lacquered with a gold storing-type enamel which adds to the attractiveness without materially affecting the total cost. Attention has also been given to the development of a grading system, and apparatus has been devised for quantitative separation of the meat and jelly and for measuring the strength of the meat broth and jelly.

Another set of experiments was concerned with the development of rancidity in poultry fat during storage. Prompt pre-cooling and freezing were found essential to the preservation of quality.

\section{Eggs}

Eggs shipped to Great Britain in ordinary storage are subject to deterioration from the growth of micro. organisms on the exterior or interior of the eggs, desiccation through loss of moisture, and thinning of the 'thick' white through loss of carbon dioxide. Preservative treatments have been tested and methods of handling investigated. Oil dipping appears to be 